\title{
Um lugar em produção: o caso da Cova da Moura
}

A place in the making: the case of Cova da Moura

Sílvia Jorge e Júlia Carolino

\section{(2) OpenEdition \\ 1 Journals}

Edição electrónica

URL: https://journals.openedition.org/sociologico/4980

DOI: $10.4000 /$ sociologico. 4980

ISSN: 2182-7427

Editora

CICS.NOVA - Centro Interdisciplinar de Ciências Sociais da Universidade Nova de Lisboa

Edição impressa

Paginação: 19-30

ISSN: 0872-8380

Refêrencia eletrónica

Sílvia Jorge e Júlia Carolino, «Um lugar em produção: o caso da Cova da Moura», Forum Sociológico

[Online], 34 | 2019, posto online no dia 19 agosto 2019, consultado o 30 março 2022. URL: http://

journals.openedition.org/sociologico/4980 ; DOI: https://doi.org/10.4000/sociologico.4980 


\title{
UM LUGAR EM PRODUÇÃO: O CASO DA COVA DA MOURA
}

\section{A PLACE IN THE MAKING: THE CASE OF COVA DA MOURA}

\author{
Sílvia Jorge \\ Faculdade de Arquitetura da Universidade de Lisboa, GESTUAL-CIAUD \\ Júlia Carolino \\ Faculdade de Arquitetura da Universidade de Lisboa, GESTUAL-CIAUD
}

\begin{abstract}
Resumo
Resultantes da ocupação e construção sem licença em terrenos públicos e/ou privados, os bairros autoproduzidos, não reconhecidos legalmente pelo poder público, tendem a ser reduzidos às suas falhas e carências, espelhadas nas designações que lhes são geralmente atribuídas, como "bairros de barracas" ou "bairros precários". Por sua vez, este sentido negativo e pejorativo acaba por influenciar ou determinar a forma como técnicos e decisores políticos leem estes territórios, tendendo-se a preconizar a demolição do tecido urbano existente, distante dos parâmetros e da imagem de cidade hegemónicos. Tomando como caso de estudo o bairro da Cova da Moura, na Amadora, convocamos os conceitos de "lugar" e de "direito ao lugar" para explorar diferentes leituras e perceções sobre este território, cruzando duas perspetivas - uma mais antropológica e outra sócio-urbanística -, num diálogo entre as dinâmicas e aspirações locais e as políticas e instrumentos de intervenção propostos ao longo do tempo. Face à existência de uma realidade local plural e negociada, propõe-se um novo olhar sociopolítico sobre a mesma, inscrito na luta pelo direito ao lugar aqui em destaque.
\end{abstract}

Palavras-chave: produção do lugar, direito ao lugar, Cova da Moura

\begin{abstract}
Following the settlement and construction without permit on public and/or private land, self-produced neighbourhoods tend to be portrayed in ways that reduce them to their problems and are expressed through designations like "slums" or "precarious settlements". These negative designations play a role in the way professionals and decision makers make sense of these territories, favouring demolitions of the existing urban tissue as solutions for realities that fail to match the hegemonic image and parameters of the city. Taking bairro da Cova da Moura as a case study, we draw on the notions of "place" and "the right to place" to explore and relate different understanding and perceptions of that territory. We resource on anthropological and on socio-urban perspectives for looking through both the local dynamics and aspirations and the policies and tools for intervention proposed over the long term. Taking into account the existence of a plural and negotiated local reality, it is proposed a new socio-political perspective, inscribed on the fight for the right to place here in highlighted.
\end{abstract}

Keywords: production of place, right to the place, Cova da Moura

\section{Introdução}

São várias as noções a que se recorre para designar os territórios de ocupação e construção não reconhecidos legalmente pelo poder público, como a Cova da Moura, no município da Amadora, com mais de 40 anos de existência. Usadas geralmente com um sentido pejorativo, denominações como "bairros de barracas", "informais" ou "precários" têm vindo a informar grande parte das iniciativas públicas, como o Programa Especial de Realojamento, que visou "[a] erradicação das barracas, uma chaga ainda aberta 
no nosso tecido social"1 . Vários autores, como Souza (2011) e Raposo (2012), destacam a necessidade de ampliar as dimensões de análise destes espaços autoproduzidos, integrando, além das suas faltas ou carências, os ganhos, as aspirações e as vivências de quem os habita e Ihes dá identidade.

Tomando como caso de estudo o bairro da Cova da Moura (Figura 1), onde a estigmatização convive com uma identidade e dinâmica cultural que o distingue e projeta para além de si (Carolino, 2015), recorremos ao conceito de lugar para explorar e cruzar diferentes leituras e perceções sobre este território, ensaiando a sua possível adequação a uma visão mais complexa e próxima das dinâmicas que o constituem, no sentido de informar políticas públicas de intervenção mais participadas e inclusivas. Em face da persistente tensão entre soluções assentes na destruição do tecido autoproduzido e aquelas que, por sua vez, saem em defesa da sua qualificação (Raposo, 2009; Carolino, 2013), poderá fazer sentido um enfoque no direito ao lugar?

A noção de "lugar", intimamente ligada à de "espaço", convoca dimensões de coerência e identidade, implicando, necessariamente, um sujeito, um limite (fronteira) e a ideia de continuidade (Tuan, 1977; Hirsch, 1995; Casey, 1996). Numa aceção mais sociológica, o lugar define-se como um nexo de relação, história e identidade (Augé, 1992), descrito por Gupta e Ferguson como "um processo histórico partilhado que diferencia o mundo ao conectá-lo" (1997, p.46). Na linha da produção do espaço
(Lefebvre, 1991), Massey (2006) propõe a definição do lugar como um evento espácio-temporal, ou um nexo aleatório de trajetórias diversas que se cruzam entre si, perspetiva que converte todo o processo de constituição do sujeito e das fronteiras do lugar numa interrogação. É esta a abordagem adotada neste texto, ao procurar olhar o bairro da Cova da Moura como "um lugar" resultante da (inter)ação de um conjunto diversificado de atores e das narrativas em torno das quais se vai negociando a sua identidade e coerência socioespacial.

À luz deste caso específico, cruzam-se duas perspetivas: uma mais antropológica, reconstituindo a história da produção do lugar na perspetiva dos seus habitantes e das entidades através das quais se organizaram para assegurar o direito a permanecer no território que ocuparam e onde construíram as suas casas; outra mais sócio-urbanística, identificando a leitura de lugar subjacente às políticas e instrumentos de intervenção propostos, tendo em conta a constituição de uma arena específica de intervenção (Raposo et al., 2012; Raposo, 2009). Num primeiro momento, o texto foca precisamente a dimensão da produção do lugar, dialogando entre as iniciativas locais e as do poder público. Num segundo momento, analisa-se o processo de (re) afirmação do direito ao lugar em face da perspetiva de demolição do tecido autoproduzido. Por fim, num terceiro momento, centra-se o olhar na Nova Geração de Políticas de Habitação, nomeadamente no $1 .^{\circ}$ Direito - Programa de Apoio ao Acesso à Habitação²

Figura $1 \triangleright$ Bairro da Cova da Moura e sua envolvente

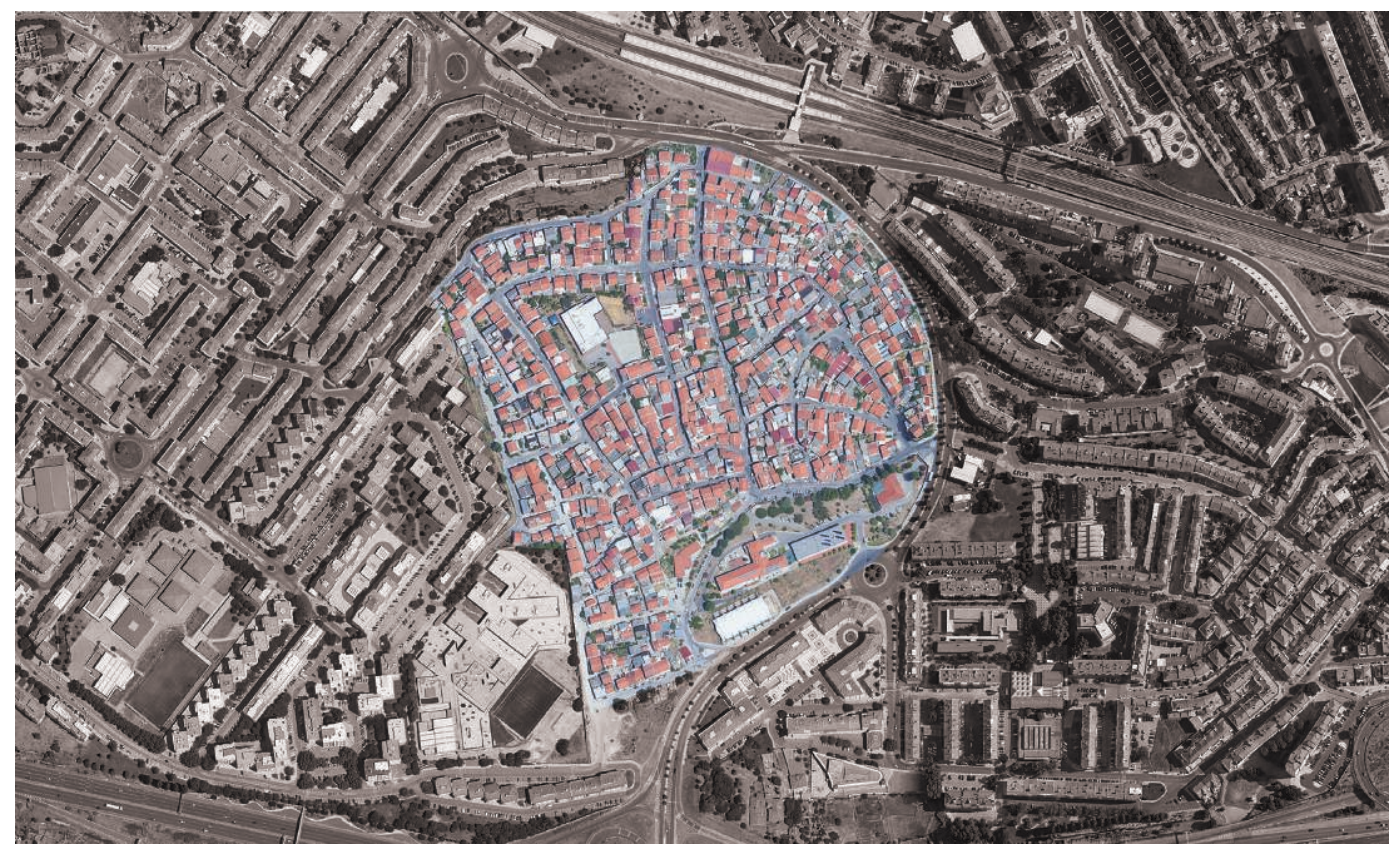

Fonte: Google Earth, 2019. Imagem trabalhada graficamente pelas autoras

\section{E Sociológico \\ … N. ${ }^{0} 34$ (II Série, 2019)
pp. 19-30}


-, questionando até que ponto este representa ou pode vir a representar uma solução para o caso da Cova da Moura. Com esta análise cruzada, pretendemos contribuir para o conhecimento das relações, e possíveis sinergias, entre a intervenção pública e os movimentos e organizações locais comprometidos com o direito ao lugar.

Os dados aqui apresentados resultam de trabaIho de campo - apoiado na observação direta e em entrevistas qualitativas, semiestruturadas - realizado pelas autoras entre 2011 e 2018, no âmbito do apoio técnico prestado à Comissão de Bairro da Cova da Moura pelo Grupo de Estudos Sócio-Territoriais, Urbanos e de Ação Local, do Centro de Investigação em Arquitetura, Urbanismo e Design da Faculdade de Arquitetura da Universidade de Lisboa (GESTUAL/ CIAUD-FAUL), bem como da pesquisa etnográfica realizada por uma das autoras entre 2012 e 2016.

\section{A produção do lugar}

Situado nos interstícios da cidade em expansão, o território onde se localiza o bairro da Cova da Moura entrou numa fase inédita de transformação quando, na década de 50, alguns proprietários rurais deram permissão aos seus trabalhadores para construírem casas em terras por si designadas. Reza a história local que a Cova da Moura terá tido a sua origem na permissão dada a José Moura, assalariado rural originário de Trás-os-Montes, para construir a sua casa na zona de uma pedreira entretanto desativada. Por esta razão, o seu filho, Manuel Moura, comerciante da Rua Principal, é hoje designado como um dos primeiros habitantes do bairro.

Os relatos que documentam a origem e desenvolvimento do bairro por cabo-verdianos, portugueses, são-tomenses, angolanos e guineenses, chegados das ex-colónias ou do interior rural de Portugal, são reveladores da história e geografia de um país em profunda transformação, bem como de um contexto colonial que se prolonga para além das independências africanas. Por outro lado, a perceção desta transformação por parte do poder público, que acompanhou desde cedo a ocupação deste território - desde o surgimento de hortas e abrigos construídos em madeira até à construção de casas de alvenaria -, dá origem a levantamentos e estudos sobre a Cova da Moura quase tão antigos quanto o próprio bairro e, em si mesmos, objetos discursivos constitutivos das narrativas-chave produtoras do lugar enquanto totalidade coerente.

Em janeiro de 1976, os Serviços de Fiscalização de Obras da então Câmara Municipal de Oeiras ${ }^{3}$ davam conta da construção de "cinco casas abarracadas em tijolo" e "caboucos para a construção de outras". Em 1977, a autarquia avançou com a realização de um estudo socioeconómico e identificou a demarcação de 203 lotes destinados a habitação, dos quais 103 se encontravam ocupados por construções de madeira, designadas por "barracas", e 90 por edifícios em alvenaria. Simultaneamente, propôs tomar posse administrativa dos terrenos e "recuperar o bairro" através da elaboração de um Plano de Urbanização, considerando que os seus habitantes teriam já "criado raízes" no lugar. Embora as medidas enunciadas não chegassem a ser postas em prática, acabariam por inviabilizar o pedido de urbanização feito pelos proprietários (Craveiro et al., 1983, pp. 18-27).

No terreno, quem construía estava ciente do risco de demolição da sua casa, desenvolvendo por isso um conjunto de estratégias que passavam sobretudo pela rápida progressão e ocupação da nova construção ${ }^{4}$. Ainda em 1977, terá sido um episódio de demolição de dezasseis casas, pela autarquia, que levou à constituição de uma Comissão de Moradores e, consequentemente, a um pedido de reunião com o então presidente da Câmara Municipal de Oeiras (Andrade Neves). Deste encontro resultou a colaboração entre a Câmara Municipal de Oeiras e a Comissão de Moradores, com vista à melhoria das condições de vida e habitabilidade do bairro. Com o apoio da autarquia na cedência de maquinaria e outros recursos, dão-se então as primeiras ligações elétricas pela EDP - Energias de Portugal -, inicia-se o traçado e a abertura de ruas, acompanhados pela atribuição da toponímia, bem como a instalação das redes de água e esgotos e a asfaltagem da Rua Principal e da Rua do Vale (Raposo \& Carolino, no prelo) (Figura 2).

Neste processo, a Comissão de Moradores adquiriu localmente especial protagonismo, que Ihe adveio não só da relação estabelecida com o município, mas também do cultivo de uma rede de relações interpessoais e alianças político-partidárias (vide Horta, 2000). Fazendo suas as preocupações do poder público, a Comissão procurou controlar a expansão do edificado, definindo e impondo determinados parâmetros construtivos, com destaque para o alinhamento das casas e a preservação da largura mínima das vias. Como recorda um antigo membro da sua equipa, "começámos a trabalhar [...] já como autoridade". Neste processo, a relação com os moradores era tensa, chegando a gerar-se momentos de aberto conflito. Para conseguir influenciar o decurso da construção, a Comissão insistiu que quem pretendesse construir deveria contactá-la previamente. A criação de uma "ficha de morador" por cada casa interessada na ligação à rede pública de água e saneamento básico foi um dos aspetos que reforçou o seu papel de interlocutor privilegiado entre moradores e poder público.

Esta conjuntura começou a alterar-se quando, em 1979, a recém-constituída Câmara Municipal da Amadora foi ganha pela Coligação Democrática Unitária $(\mathrm{CDU})^{5}$. Em 1981, a nova autarquia rei- 
Figura $2 \gg$ Planta de arruamentos, executado pela Comissão de Moradores

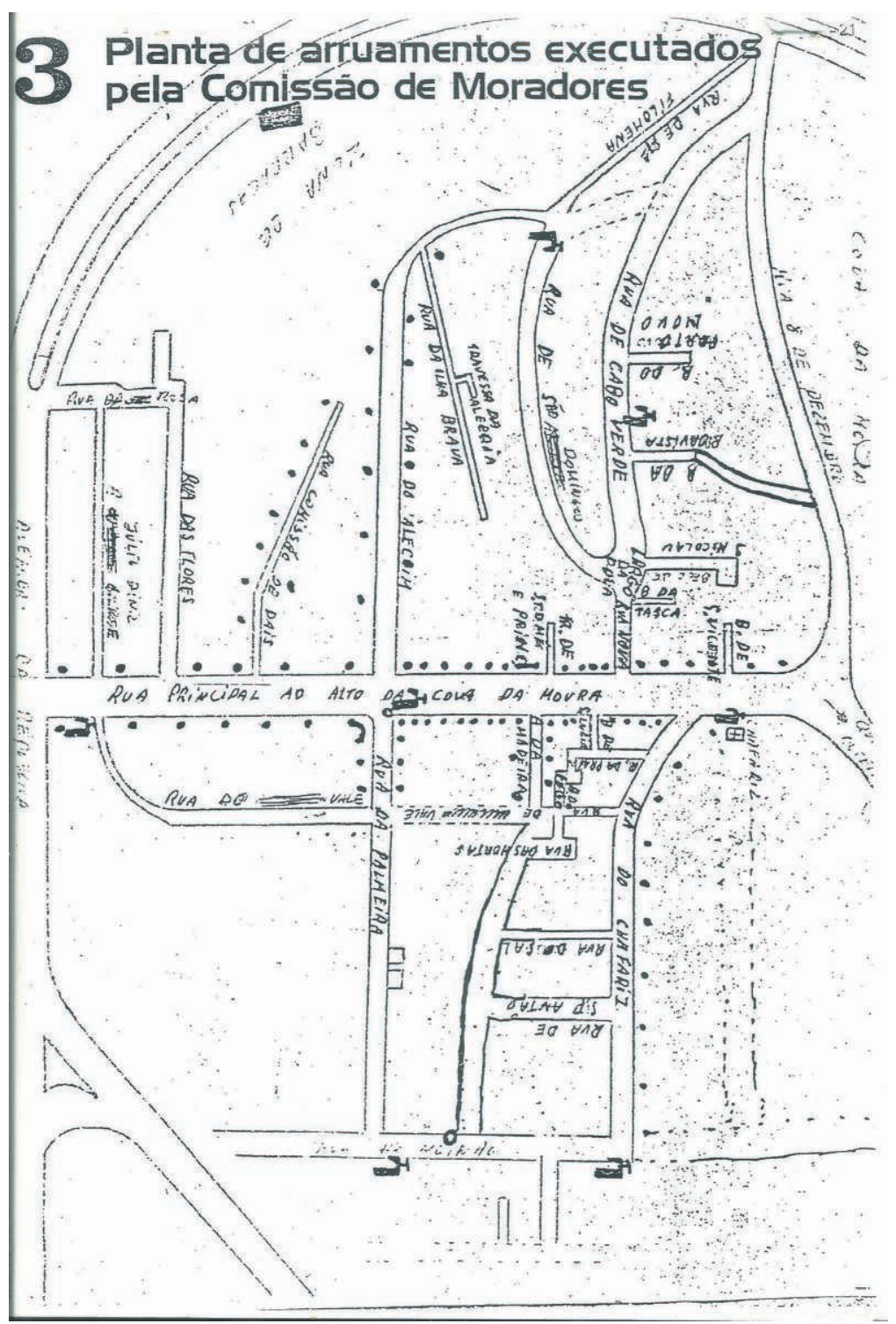

Fonte: Craveiro et al., 1983, p. 21

terou a posição do anterior executivo, indeferindo uma vez mais os pedidos de urbanização por parte dos proprietários do terreno. Um ano mais tarde, deliberou a expropriação do terreno por utilidade pública e avançou com uma "avaliação socioeconómica, jurídica e financeira da recuperação do bairro", conducente a propostas concretas de "recuperação" (Craveiro et al., 1983, pp. 19, 27-28).

Surgiu assim em 1983 o primeiro grande estudo da Cova da Moura (Craveiro et al., 1983), realizado por técnicos municipais, no qual se identificou um total de 836 edifícios, predominantemente em alvenaria, e uma ocupação em quarteirões muito mais extensiva do que a registada anteriormente
(Figura 3). Destacava-se, igualmente, o risco de densificação do edificado, por via da verticalização, chamando-se a atenção para o surgimento de uma "fase especulativa deveras preocupante que se vem delineando em torno desta ocupação". Os técnicos instavam a "uma intervenção decidida da Administração a todos os seus níveis (Central e Local), que discipline e regre a dinâmica construtiva" (Craveiro et al., 1983, p. 98), defendendo uma estratégia que valorizasse as dinâmicas locais e processos acompanhados de autoconstrução evolutiva. Não obstante a criação de um gabinete local, as medidas delineadas pela autarquia não chegaram, no entanto, a concretizar-se.

Na Cova da Moura, manteve-se a proximidade entre a Comissão de Moradores e a recém-criada Junta de Freguesia da Buraca, onde um dos elementos fundadores da Comissão de Moradores foi eleito pelo Partido Socialista como membro do poder executivo. Data deste período o loteamento realizado na parte sudeste do bairro, a última a ser ocupada, liderado pela Comissão de Moradores e que, embora não fosse legalmente reconhecido pelo Estado, contou com a colaboração da Junta de Freguesia. Uma preocupação em atribuir estes lotes a "portugueses" refletia um novo esforço no sentido de assegurar a "modernidade" e "boa reputação" da Cova da Moura, através da seleção criteriosa das pessoas que ocupariam uma zona particularmente visível do bairro a partir "de fora". Ironicamente, foi nesta zona que nasceu, em 1984, uma outra organização de moradores - a Associação Cultural Moinho da Juventude -, empenhada no empoderamento dos habitantes em situação de maior exclusão, promovendo a cultura e identidade africanas da Cova da Moura6.

Sem recorrer à Comissão de Moradores, este grupo de vizinhos, dependentes de um chafariz localizado na zona sudeste do bairro, organizou-se para, interpelando diretamente a Câmara Municipal, aceder à rede de água e saneamento básico, tendo recenseado 900 habitantes com esta necessidade, 
Figura 3 Levantamento das tipologias construtivas (1983): a verde 'edifícios em alvenaria', a amarelo 'casas abarracadas' e a vermelho 'barracas'

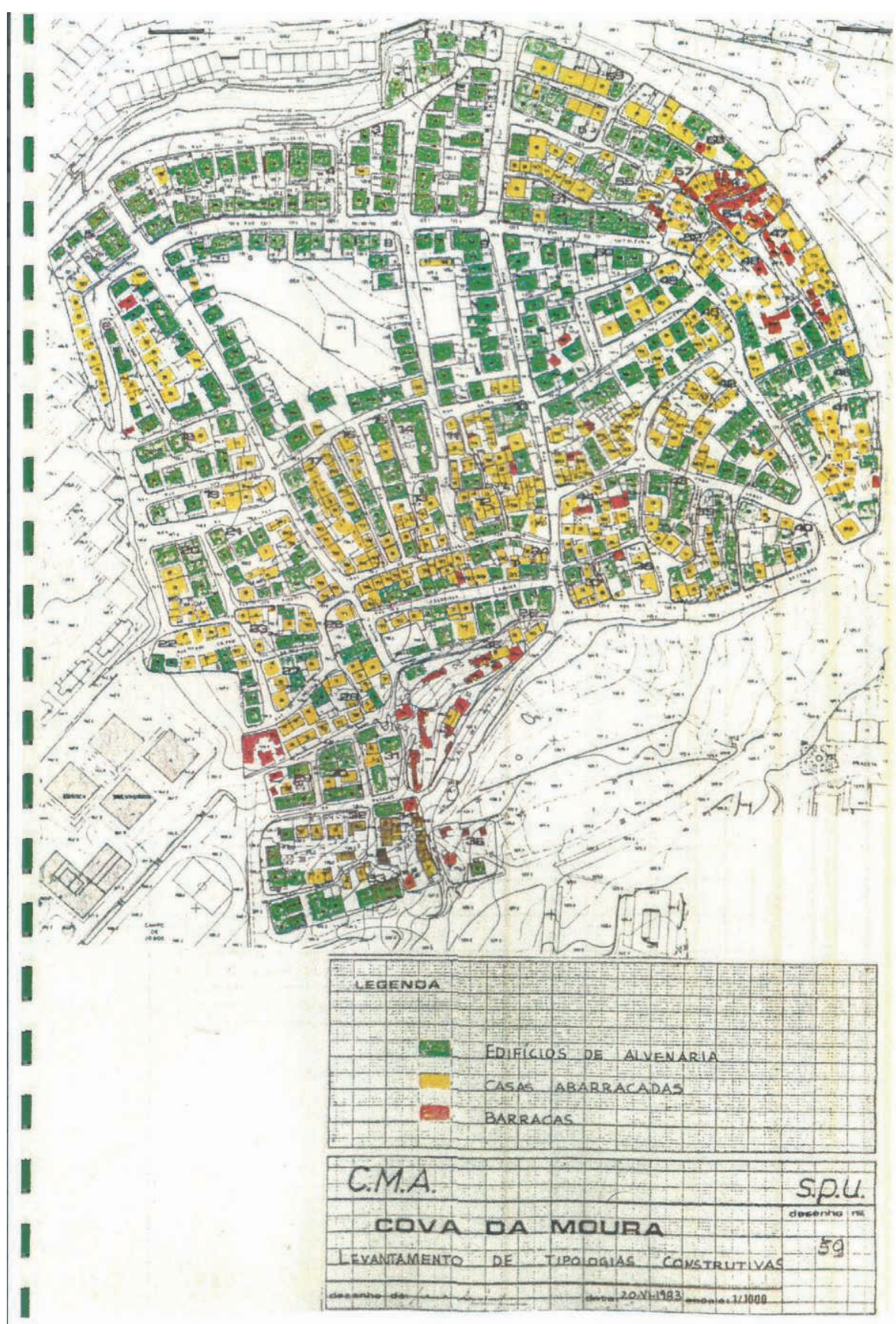

Fonte: Craveiro et al., 1983, p. 59

dispostos a contribuir para a resolução do problema. Em paralelo, criou uma biblioteca comunitária, destinada sobretudo às crianças, e, em diálogo com o Sindicato das Empregadas Domésticas (ocupação de muitas moradoras do bairro), envolveu-se na melhoria das suas condições de trabalho. Com a sua própria rede de relações e, ao longo do tempo, alguma projeção mediática, a Associação Cultural Moinho da Juventude veio progressivamente desafiar o protagonismo assumido anteriormente pela Comissão de Moradores, facto a que não será também indiferente o crescimento populacional associado sobretudo à migração laboral cabo-verdiana caraterística das décadas de 80 e 90 
(vide Malheiros \& Esteves, 2013). Ao apostar na importância da cultura como fator de integração e desenvolvimento, o Moinho da Juventude promove, e projeta na sociedade portuguesa, práticas culturais de tradição cabo-verdiana, como é o caso do Kola San Jon (Figura 4) - festa cabo-verdiana de São João -, obtendo, em 2013, a sua inscrição no Inventário Nacional do Património Cultural Imaterial?.

Figura $4 \triangleright$ Cultura e identidade na Cova da Moura. A Festa de Kola San Jon, 2012

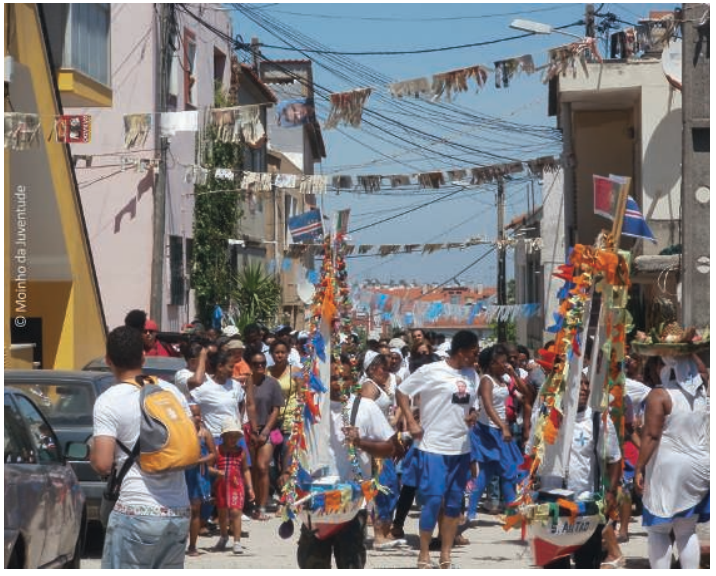

Fonte: Moinho da Juventude

De um modo geral, pode dizer-se que, ao longo da década de 80 , se foi consolidando e diversificando a vida institucional do bairro. No mesmo período, pessoas ligadas à Comissão de Moradores haviam lançado já uma outra organização, que designaram por Clube Recreativo ${ }^{8}$. Também nesta década foi criada a Paróquia da Buraca e, com ela, o Centro Social e Paroquial. Nos anos seguintes, estas organizações criaram um conjunto diversificado de serviços destinados aos moradores, ao nível do apoio à infância, jovens, idosos, formação e emprego, documentação e outros. Entrou igualmente em funcionamento a escola pública do primeiro ciclo do ensino básico da Cova da Moura. Simultaneamente, a relação dos moradores com o bairro diversifica-se: por um lado, aos primeiros habitantes, que ali construíram as suas casas, junta-se a geração já nascida na Cova da Moura; por outro, o arrendamento expande-se progressivamente, até atingir valores tão expressivos quanto os dos donos das casas. No entanto, enquanto isso, a questão da regularização fundiária e urbanística do bairro permaneceu em aberto.

Com a eleição de Joaquim Raposo, do Partido Socialista, para presidente da autarquia, em 1993, depois de 12 anos de governação CDU, cresceram as esperanças, em especial por parte das associações politicamente mais próximas - a Comissão de Moradores e o Clube Recreativo -, de que fosse retomada a colaboração que marcara as relações com o congénere de Oeiras, no final da década de 70. Contudo, os tempos eram outros.

\section{(Re)afirmação do direito ao lugar}

O forte investimento e envolvimento municipal no período após o 25 de Abril de 1974, começou a diminuir com o privilegiar, a nível nacional e internacional, de políticas neoliberais, dirigidas para a lógica de mercado, assente na propriedade privada individual (vide Raposo \& Jorge, 2017; Hibou, 2011) e que equaciona as questões da qualificação urbanística e habitacional como objetos de intervenção iminentemente técnica. A partir de finais da década de 80, com o aumento do mercado imobiliário e o anúncio da exibição da capital a nível internacional, através da Lisboa Capital Europeia da Cultura em 1994 e da Expo"98, registou-se um aumento da pressão para lidar com a grande visibilidade e extensão dos então denominados "bairros de barracas", localizados às portas de Lisboa (vide Cachado, 2013; 2018). Apoiado numa visão estigmatizada e estereotipada destes territórios, o Programa Especial de Realojamento (PER), publicado em 1993, surgiu enquanto resposta a este problema. Dirigido às áreas metropolitanas de Lisboa e do Porto, este programa assentou em três objetivos: erradicar as "barracas", envolver fortemente os municípios no processo de erradicação preconizado e potenciar, com o realojamento, uma mudança no estilo de vida dos moradores, partindo-se da ideia de que condições de habitação degradadas favorecem "comportamentos desviantes" (Cachado, 2013). A Câmara Municipal da Amadora recenseou, ao abrigo do PER, 6755 agregados familiares a realojar, sendo um dos municípios com mais famílias a viver nas designadas "barracas" (Salgueiro, 1985, p. 63). Apenas uma pequena parte dos habitantes do bairro da Cova da Moura ${ }^{9}$ foi considerada neste recenseamento (57 agregados). Tal não refletiria, contudo, uma imagem ou abordagem de intervenção por parte da autarquia necessariamente distintas, recaindo sobre a Cova da Moura uma visão igualmente estigmatizada e estereotipada, vinculada à noção de bairro "crítico" e "degradado". Nestes anos, preparam-se e entram em vigor instrumentos-chave para uma intervenção municipal ao nível do ordenamento do território, como a classificação da Cova da Moura como "área estratégica de desenvolvimento municipal", no âmbito do primeiro Plano Diretor Municipal, ratificado em 1994, e a atribuição do estatuto de "área crítica de recuperação e reconversão urbanística" (ACCRU) ${ }^{10}$. No diploma, o bairro é descrito como "uma estrutura habitacional, social e ambiental bastante degradada, com graves insuficiências de infra-estruturas urbanísticas, espaços verdes e equipamentos sociais", cabendo à Câmara Municipal "promover, em colaboração com as demais entidades interessadas, as 
acções e o processo de recuperação e reconversão urbanística da área".

A partir de 2000, a Cova da Moura, a par da Brandoa, foi abrangida pelo programa comunitário URBAN II, direcionado para a promoção e aplicação de "estratégias inovadoras de revitalização socioeconómica sustentável dos centros urbanos" ou dos "subúrbios em crise das grandes cidades" (CCDR, IFDR, 2010, p. 11). No âmbito do URBAN, o bairro é descrito como tendo uma "malha confusa", com "construções amontadas" e uma acessibilidade interna difícil devido à forte inclinação e à existência de passagens estreitas (CCDR, IFDR, 2010, pp. 19-20). Além das suas características físicas, aborda-se o problema da toxicodependência e de "um conjunto de atividades ilícitas" (CCDR, IFDR, 2010, pp. 19-20). Assumiram-se como objetivos estratégicos: requalificar o ambiente urbano e valorizar o espaço público; integrar a população local; revitalizar o ambiente social; e valorizar o contexto socioeducativo da população juvenil (CCDR, IFDR, 2010 , p. 22). Destacam-se os melhoramentos realizados no pavilhão desportivo, no Jardim Central da Buraca e no Jardim 25 de Abril, nas imediações do bairro, que acabariam por beneficiar de alguma forma os habitantes do bairro (vide Lages, 2017).

Em 2002, a Câmara Municipal avançou com a elaboração do primeiro Plano de Pormenor para o bairro. Desenvolvido por um gabinete privado Vasco da Cunha, Estudos e Projetos -, o Plano de Pormenor apontava para a necessidade de substituição de grande parte do edificado, de "abrir o bairro ao exterior" e de promover a construção de novos equipamentos e espaços verdes. Apoiado na demolição de cerca de $80 \%$ do edificado existente, propunha o realojamento dos moradores in situ, em "novos fogos sociais, em tipologia de acordo com o seu agregado familiar", mediante o pagamento de uma renda calculada em função dos rendimentos auferidos. Apenas para uma parte do bairro (156 edifícios, na zona norte) se previa a qualificação do tecido existente, recebendo os donos das casas em questão o estatuto de proprietários, responsáveis pela compra do terreno ocupado e pelo pagamento das infraestruturas necessárias, das taxas de legalização e de outras despesas inerentes ao processo (Câmara Municipal da Amadora, 2002).

Esta proposta suscitou grande contestação entre moradores e organizações locais, unidos pela qualificação do bairro, constituindo-se em 2004 a Comissão de Bairro da Cova da Moura, que conta, desde o início, com o apoio de uma equipa da Faculdade de Arquitetura da Universidade de Lisboa (então Universidade Técnica de Lisboa), nomeadamente ao nível da componente técnica. Estratégias e propostas alternativas à tabula rasa, de foro académico, são apresentadas no workshop "A reabilitação do bairro é possível se a gente quiser", no quadro da festa anual Kola San Jon, em 2005. No mesmo período, a Associação de Moradores (antiga Comissão de Moradores) liderou um processo coletivo que levou 60 moradores, a residir na Cova da Moura há mais de trinta anos, a formalizar uma ação de usucapião. Estes desenvolvimentos acabariam por reforçar o posicionamento da Comissão de Bairro, que representou os moradores e organizações locais ao longo da maior iniciativa pública de intervenção que se seguiu: a Iniciativa Bairros Críticos (IBC) ${ }^{11}$.

Esta iniciativa, desencadeada, entre 2005 e 2012, em três bairros piloto, um deles a Cova da Moura, pretendia "estimular e testar soluções institucionais, procedimentais e tecnológicas inovadoras em termos de concepção, implementação e avaliação da acção pública em áreas urbanas críticas". Assente num envolvimento interministerial, na participação de parceiros locais e em parcerias público-privadas, assumia uma mudança de paradigma ao nível da abordagem e intervenção sócio-territorial integrada (vide Lages, 2017). Coordenada pelo Instituto de Habitação e Reabilitação Urbana (IHRU) e, numa fase inicial, acompanhada de perto pela Secretaria de Estado do Ordenamento do Território, a Iniciativa Bairros Críticos deparou-se no terreno com uma realidade claramente polarizada, que opunha, por um lado, a Comissão de Bairro, em representação das organizações locais e dos moradores, e, por outro, a Câmara Municipal (vide Carolino, 2013).

O diagnóstico participado (Malheiros, Vasconcelos \& Alves, 2006a), validado por um Grupo de Parceiros Locais ${ }^{12}$, serviu de base aos eixos estratégicos delineados no Plano de Ação definido para o Bairro (Malheiros, Vasconcelos \& Alves, 2006b), que visava: a legalização e requalificação urbana, bem como a promoção de uma nova imagem do território, através do reforço da segurança, da sustentabilidade ambiental e da qualificação e diversificação da oferta cultural (Sousa, 2012, p. 31). Com base neste Plano de Ação, o IHRU solicitou ao Laboratório Nacional de Engenharia Civil (LNEC) o estudo das condições de habitabilidade do edificado e das necessidades de reabilitação, desenvolvido ao longo de 2008, com o apoio de mediadores locais (vide Ascensão, 2013; Carolino, 2013). No levantamento e análise efetuados a Cova da Moura foi caracterizada pela presença de problemas habitacionais, construtivos e urbanísticos, definindo-se três tipos de casos: de "reabilitação ligeira", de "reabilitação média" e de "reabilitação profunda" (Coelho et al., 2008).

Foi assim atribuído ao Plano de Pormenor um papel fundamental, uma vez que determinaria o edificado a reabilitar e a demolir. Tendo realizado e deixado disponível (sob a forma de uma base de dados de acesso restrito) uma caracterização detalhada (edifício a edifício), a equipa do LNEC sublinhou a necessidade de "uma articulação pormenorizada e estratégica" no âmbito dos trabalhos 
a desenvolver para a elaboração deste instrumento de ordenamento territorial, a fim de "potenciar as melhores características do espaço urbano e do edificado preexistentes com as melhores intenções urbanas e residenciais" (Coelho et al., 2008, p. 39).

Em 2010 iniciaram-se os trabalhos associados à elaboração do Plano de Pormenor, atribuídos (por concurso público internacional) ao mesmo gabinete que realizara a proposta de 2001 . Após várias etapas preparatórias, discutidas com a Câmara Municipal e, só depois, com a Comissão Executiva da IBC da Cova da Moura (onde tinha assento a Comissão de Bairro), o Gabinete apresentou em 2012 os primeiros cenários de intervenção, para debate, nos quais o realojamento in situ (dos moradores que declararam querer permanecer no bairro) foi contemplado, mas a par da demolição de grande parte do edificado, ainda que possivelmente dentro de tipologias mais próximas das existentes. Esta possibilidade não teve a aprovação da Comissão de Bairro, que contrapropôs com um processo participado, à escala do quarteirão, partindo da premissa da qualificação do tecido existente, sempre que possível (vide Carolino, 2013). Contudo, o processo foi, entretanto, interrompido. Em Março de 2012, o IHRU retirou-se, alegando falta de verbas para continuar, e a IBC foi formalmente extinta em dezembro do mesmo ano. Nos anos seguintes, as associações locais, apoiadas pela Faculdade de Arquitetura, procuraram articular uma via alternativa, participada, entregando ao município, em 2013, três propostas de intervenção assentes na qualificação gradual do espaço público, discutidas e construídas com as organizações locais e com grupos de habitantes. Sem qualquer resposta, as expetativas em torno da regularização e qualificação do bairro apenas reemergem recentemente, na sequência: por um lado, da reaproximação da família Canas, a maior proprietária dos terrenos onde se localiza a Cova da Moura, propondo a negociação de uma compensação ou uma permuta ${ }^{13}$; por outro, da criação da Secretaria de Estado da Habitação.

\section{Geração do "1.0 Direito"}

Perante a persistência de problemas estruturais no setor da habitação, denunciados, quer pelas associações, movimentos e coletivos da sociedade civil que lutam há vários anos pelo direito à habitação, quer inclusivamente pela relatora das Nações Unidas para a Habitação Adequada ${ }^{14}$ (UN, 2017), o governo português avançou em meados de 2017 com a criação de uma Secretaria de Estado da Habitação. Pouco tempo depois, foi oficialmente lançada uma Nova Geração de Políticas, que apresenta a habitação e a reabilitação como "instrumentos-chave para a melhoria da qualidade de vida das populações" e assume a missão de "[g]arantir o acesso de todos a uma habitação adequada" (SEH, 2017, p. 3). Mais recentemente, em fevereiro de 2019, foi criado o Ministério das Infraestruturas e da Habitação, reiterando a importância do tema da habitação no panorama político atual.

Propõe-se, no quadro da Nova Geração de Políticas, um novo olhar, mais amplo e transversal, sobre a problemática habitacional. Segundo se sublinha no documento orientador, a noção de "habitação" deve ser lida no sentido amplo de "habitat" e orientada para as pessoas, procurando "[c]riar as condições para que tanto a reabilitação do edificado como urbana passem de exceção a regra" (SEH, 2017 , p. 3). Pretende-se transitar de uma política de habitação apoiada na construção de novos alojamentos, como o PER, focada "na casa" e dirigida para a oferta pública de habitação destinada aos grupos de menores recursos, para uma política que privilegie a reabilitação e o arrendamento, dirigida a todos os que não conseguem aceder atualmente a uma habitação no mercado (SEH, 2017, pp. 6-8).

A definição e apresentação desta Nova Geração de Políticas foi acompanhada do primeiro Levantamento Nacional das Necessidades de Realojamento Habitacional realizado em Portugal, coordenado pelo IHRU e posto em prática através de um inquérito dirigido aos municípios. Procurou-se, através deste levantamento, sinalizar as atuais necessidades habitacionais a nível nacional, conhecer o número de famílias a viver em condições precárias e sistematizar as soluções preconizadas pelos municípios para a resolução destas mesmas carências (IHRU, 2018, p. $1)$. Os resultados revelaram a efetiva necessidade de medidas ao nível da habitação, tendo sido identificadas 25762 famílias em situação de carência, correspondentes a 14748 edifícios e 31526 fogos. O estudo revelou também ser a Área Metropolitana de Lisboa um dos contextos onde mais se coloca o problema, estando aí concentrados mais de metade dos casos identificados (IHRU, 2018, pp. 1-2) Os municípios da Amadora, Loures e Almada sinalizam, juntos, mais de 1000 famílias em situação de grave carência habitacional, a viverem sobretudo no que o inquérito designa de "barracas e construções precárias" (IHRU, 2018, p. 11). A Amadora destaca-se no topo da lista, com 2839 famílias identificadas. Um levantamento municipal, datado de dezembro de $2017^{15}$, sinaliza 35 "bairros degradados" no seu território, grande parte deles dados como "extintos", ao abrigo do PER, sendo a Cova da Moura apontada como um dos oito ainda "existentes".

No quadro da Nova Geração de Políticas de Habitação, foi publicado em junho de 2018 o $1 .{ }^{\circ}$ Direito - Programa de Apoio ao Acesso à Habitação ${ }^{16}$ -, direcionado especificamente para os casos de maior precariedade habitacional, podendo aceder a este programa a pessoa ou o agregado que, cumulativamente, viva em condições indignas e esteja em situação de carência financeira (artigo 6.0). 
Outro critério de elegibilidade é o de ser detentor de cidadania portuguesa ou título de residência válido no território nacional, facto que levanta a questão de até que ponto se salvaguarda, assim, o acesso a uma habitação condigna enquanto um direito universal. Contemplando a possibilidade de uma intervenção mais territorial, define modalidades de intervenção para "núcleos precários" e "núcleos degradados". Por "núcleos precários", entendem-se as "construções não licenciadas, acampamentos ou outras formas de alojamento precário ou improvisado" - "mantendo entre si contactos subsumíveis do conceito de relações de proximidade e vizinhança" (artigo $1 .^{\circ}$ ) -, para os quais se prevê a possibilidade de realojamento em novas construções ${ }^{17}$ ou a reabilitação do tecido preexistente, inserida num processo de legalização, se garantidas condições mínimas de habitabilidade (n. ${ }^{\circ} 3$ do artigo $11 .^{\circ}$ ). Neste caso, além das soluções individuais de realojamento, contempla-se uma solução habitacional promovida pelo município, diretamente ou através de soluções coletivas apresentadas pelos próprios beneficiários, "[a]grupados sob a forma de associação de moradores ou de cooperativa de habitação e construção" (n.o 2, alínea c) do artigo 11.0 $)^{18}$. Os "núcleos degradados", por sua vez, referem-se a "áreas urbanas degradadas cujas edificações [...] constituam núcleos habitacionais com uma identidade própria e diferenciada", como as chamadas ilhas, pátios ou vilas (artigo $12 .^{\circ}$ ), para os quais se preconiza a reabilitação, a efetuar pelos proprietários das edificações ou por entidades gestoras, no caso de operações de reabilitação urbana sistemáticas (n. ${ }^{\circ} 4$ do artigo $\left.12 .^{\circ}\right)^{19}$. Desde que a situação o justifique, contempla-se ainda a conjugação de diferentes soluções, como a aquisição de terrenos e a reabilitação dos edifícios neles existentes (artigo $28 .{ }^{\circ}$ ), apontando assim saídas para casos em que a questão fundiária seja necessariamente o primeiro passo a dar.

Ao nível da construção e implementação das soluções apresentadas, destaca-se a possibilidade de cooperação e participação de diferentes tipos de atores, públicos ou privados, na definição e concretização dos procedimentos que assegurem as soluções habitacionais encontradas (artigo 3. ${ }^{\circ}$ ). A par de "beneficiários diretos" - as pessoas que preenchem os requisitos de acesso -, o Programa define "entidades beneficiárias", que podem receber apoio para a promoção de soluções habitacionais a pessoas e agregados elegíveis na qualidade de "beneficiários diretos". Podem participar, com este estatuto, o Estado e as empresas, entidades ou institutos públicos, bem como as misericórdias e instituições particulares de solidariedade social (IPSS) e pessoas coletivas de interesse público, as associações de moradores, as cooperativas de habitação e construção e, ainda, os proprietários de frações ou prédios localizados em núcleos degradados (artigo $26 .^{\circ}$ ). Por último, tendo em conta a sua "proximidade com os cidadãos e com o território" (preâmbulo), é atribuído às autarquias um "papel imprescindível e instrumental". Cabe ao município, antes de mais, definir uma estratégia local de habitação e priorizar as soluções habitacionais que pretender ver desenvolvidas no seu território, devendo as candidaturas enquadrar-se nessa mesma estratégia (artigo 30.).

No âmbito deste novo pacote de políticas, a Secretaria de Estado da Habitação promoveu um amplo debate e a divulgação das medidas anunciadas, quer na fase de discussão pública, quer por ocasião da sua entrada em vigor. Foi neste contexto que os representantes das associações que integram a Comissão de Bairro da Cova da Moura tomaram contacto com as medidas anunciadas e procuraram recolocar na agenda pública o caso do seu bairro, ainda pendente de uma intervenção pública dirigida à resolução da situação fundiária, urbanística e habitacional. Em janeiro de 2018 reúnem com a secretária de Estado, Ana Pinho, e em setembro de 2018 obtêm esclarecimentos adicionais por parte do corpo técnico do IHRU, passando a depositar algumas esperanças no $1 .^{\circ}$ Direito.

Embora seja necessário conhecer, antes de mais, a estratégia de habitação definida pelo município, este programa levanta algumas questões, analisadas à luz do caso do Bairro da Cova da Moura. Ao permitir, enquanto situações específicas, a procura de soluções coletivas e o envolvimento de atores locais, como as associações de moradores e outras formas de organização dos beneficiários, o programa poderá encontrar respostas para casos como o da Cova da Moura, há muito em aberto, incorporando as dinâmicas complexas e participadas próprias do lugar. No entanto, as categorias territoriais propostas, de "núcleo precário" e "núcleo degradado", apresentam algumas limitações. Focadas quase exclusivamente nas características urbanísticas e nas suas dimensões mais problemáticas, estas categorias transportam em si uma carga negativa e pejorativa, que as aproxima das situações abrangidas pelo congénere PER, não integrando como recursos para a intervenção a história e a identidade consolidadas no bairro enquanto lugar. $\mathrm{O}$ potencial enfoque territorial é limitado, igualmente, ao considerar-se como beneficiários diretos do 1.0 Direito exclusivamente as famílias em situação de carência financeira, excluindo uma grande parte dos moradores, entre eles os proprietários das construções com melhores condições de habitabilidade, inviabilizando, assim, uma intervenção integrada e abrangente, à escala de todo o bairro. Da mesma forma, ficam ainda fora do programa os moradores que não tenham a sua situação regularizada no país, impedindo, como referido anteriormente, a leitura do direito à habitação enquanto direito universal. 
Ao atribuir um papel também aos proprietários, a categoria "núcleo degradado" aproxima-se mais da realidade complexa que caracteriza, como vimos, a composição e as dinâmicas da Cova da Moura, embora, na sua definição, ambas as categorias procurem, à sua maneira, dar conta de elementos que remetem para a dimensão do lugar: no caso dos "núcleos precários", contemplam-se as "relações de proximidade e de vizinhança" (artigo 11. ${ }^{\circ}$, ponto 1 ), enquanto no caso dos "núcleos degradados" se sublinha a sua suposta "identidade própria e diferenciada no espaço urbano" (artigo $12 .^{\circ}$, ponto 1 ).

\section{Conclusões}

Apesar do esforço financeiro na promoção pública de habitação nas últimas décadas, várias famílias continuam em Portugal a aguardar o acesso a uma habitação adequada e a condições de vida condignas ou, simplesmente, a salvaguarda do direito ao lugar e à habitação. Com a recém-criada Secretaria de Estado da Habitação, comprometida em garantir o acesso de todas e todos a uma habitação e a passagem da reabilitação de exceção a regra, que outras possibilidades se levantam ao nível dos territórios autoproduzidos?

Cruzando uma análise da produção do lugar, à luz do caso do bairro da Cova da Moura, com a das perspetivas recentemente abertas pela Nova Geração de Políticas de Habitação, procurámos averiguar de que modo, e até que ponto, poderá o programa 1.0 Direito, dirigido para os casos de maior precariedade habitacional, contribuir para a regularização deste território autoproduzido. A par de elementos que surgem como potencialmente favoráveis a este fim, identificámos outros que poderão ser limitadores, ao reduzir a poucas dimensões, iminentemente técnicas e jurídicas, uma realidade muito mais complexa, característica do processo de produção do lugar.

$\mathrm{Na}$ análise levada a cabo, vimos que a constituição do bairro, com a sua história e identidade específicas, envolveu um longo processo, marcado por formas de ação e visões de possibilidade diferentes entre si, revelando uma realidade local plural e negociada, marcada por distintos protagonismos. Por outro lado, vimos também que a mesma incorporou desde muito cedo a perceção de que o bairro não se faria e defenderia apenas com os que ali habitam, desenvolvendo-se antes em relação com o poder público, relação essa também ela multifacetada e mutável ao longo do tempo. Nesta análise, foram-se revelando as estratégias desenvolvidas pelos atores, com o intuito de assegurar um direito a permanecer num espaço da cidade cada vez mais central e, por isso mesmo, apetecível do ponto de vista imobiliário, onde foram desenvolvendo formas de relação, identificação e pertença próprias do lugar. Em face desta complexidade, precisamos de nos demarcar de uma visão estritamente técnica dos desafios em aberto, retomando um olhar sociopolítico que fomos designando como de luta pelo direito ao lugar.

\section{Notas}

1 Preâmbulo do Decreto-Lei n. ${ }^{\circ}$ 163/1993, de 7 de maio.

2 Decreto-Lei n. ${ }^{\circ}$ 37/2018, de 4 de junho.

${ }^{3} \mathrm{O}$ território em questão era, à data, parte integrante da autarquia de Oeiras. Apenas em 1979 foi criado o município da Amadora, de que o bairro da Cova da Moura faz hoje parte.

${ }^{4}$ Era comum o esforço de, reunindo familiares, amigos e/ /ou contratando alguém, construir intensivamente durante um fim-de-semana, para modo evitar que a obra fosse identificada pelas autoridades antes de ter um teto e dar sinais de ser ocupada para habitação.

${ }^{5}$ A CDU é uma coligação formada pelo Partido Comunista Português e pelo Partido Ecologista "Os Verdes".

${ }^{6}$ Sobre a projeção de uma identidade cabo-verdiana para o bairro, ver o documentário realizado e produzido por Rui Simões em 2008, intitulado Ilha da Cova da Moura.

7 Direção-Geral do Património Cultural, Anúncio n. ${ }^{\circ}$ 323/2013, publicado em Diário da República, 2. a série, N. ${ }^{\circ} 200$, de 16 de outubro de 2013.

8 "O Clube", como é conhecido ainda hoje localmente, alterou mais tarde a designação para "Associação de Solidariedade Social do Alto da Cova da Moura".

9 Levantamento disponível em: http://www.cm-amadora. pt/intervencao-social/habitacao-social.html (acesso realizado em outubro de 2018).

10 Decreto n. ${ }^{\circ}$ 53/2003, de 11 de dezembro.

${ }^{11}$ Resolução do Conselho de Ministros n. ${ }^{\circ}$ 143/2005, de 2 de agosto, publicada em Diário da República, I Série - B, de 7 de setembro de 2005.

12 O Grupo de Parceiros Locais era composto por um total de 28 instituições.

${ }_{13}$ Ver, por exemplo, o artigo intitulado "A Cova da Moura tem dono e todos lucram à nossa conta", assinado por Valentina Marcelino e publicado no Diário de Notícias a 24 de outubro de 2016.

${ }^{14}$ Na sequência da sua visita a Portugal, em dezembro de 2016.

15 Disponível em: http://www.cm-amadora.pt/intervencao-social/habitacao-social.html (acesso realizado em outubro de 2018).

${ }^{16}$ Decreto-Lei n. ${ }^{\circ}$ 37/2018, de 4 de junho.

17 Mediante a aquisição de terrenos e a construção ou aquisição de edifícios habitacionais.

${ }^{18} \mathrm{Na}$ mesma alínea especifica-se, ainda: "para atribuição de habitações em arrendamento ou propriedade resolúvel".

19 Caso os proprietários se oponham a esta operação, está previsto o recurso à tomada de posse administrativa ou a expropriação por utilidade pública (n. ${ }^{\circ} 4$ do artigo $12 .^{\circ}$ ). 


\section{Referências bibliográficas}

Ascensão, E. (2013). Following engineers and architects through slums: the technoscience of slum intervention in the Portuguese-speaking landscape. Análise Social, 206(XLVIII), 154-180.

Augé, M. (2005). Não lugares: introdução a uma antropologia da sobremodernidade. Venda Nova: Bertrand.

Cachado, R. (2013). O Programa Especial de Realojamento. Ambiente histórico, político e social. Análise Social, 206(XLVIII), 135-152.

Cachado, R. (2018). O fim das políticas de habitação social? In A. Carmo, E. Ascensão, A. Esteves (Eds. ), A Cidade em Reconstrução: leituras críticas, 2008-2018 (pp. 155-162). Odivelas: Outro Modo Cooperativa Cultural.

Câmara Municipal da Amadora (2002). Plano de Pormenor do Bairro do Alto da Cova da Moura. Estudo prévio. Policopiado.

Carolino, J. (2013, março). Contribuições de um enfoque antropológico no lugar para a temática da requalificação habitacional. O caso da Cova da Moura. In Atas do Segundo Congresso Internacional da Habitação no Espaço Lusófono, Lisboa: LNEC.

Carolino, J. (2015). Kola San Jon e o direito à cidade em Lisboa. Colóquio Cultura Proibida, Património Estimado (pp. 56-64). Amadora: ACMJ.

Casey, E. (1996). How to Get from Space to Place in a Fairly Short Stretch of Time. Phenomenological Prolegomena. In S. Feld \& K. Basso (Eds.), Senses of Place (pp. 13-52). Santa Fe: School of American Research Press.

Coelho, A. B., et al. (2008). Colaboração do LNEC na Análise das Condições de Habitabilidade do Edificado Existente no Bairro do Alto da Cova da Moura. Avaliação das Necessidades de reabilitação do Edificado. Relatório de Síntese. Lisboa: LNEC.

Comissão de Coordenação e Desenvolvimento Regional de Lisboa e Vale do Tejo (CCDR) e Instituto Financeiro do Desenvolvimento Regional (IFDR) (2010). Relatório de Execução Final, Programa de Iniciativa Comunitária Urban II Amadora (Damaia-Buraca) 2000-2006. Lisboa: CCDR e IFDR.

Craveiro, T., et al. (1983). Caracterização do Bairro Alto da Cova da Moura. Amadora: Departamento de Urbanismo da Câmara Municipal da Amadora.

Decreto n.o 53/2003 de 11 de Dezembro. Diário da República n.o 285/2003, Série I-B. Lisboa: Ministério das Cidades, Ordenamento do Território e Ambiente

Decreto-Lei n. ${ }^{\circ}$ 163/1993 de 7 de Maio. Diário da República n.o 106/1993, Série I-A. Lisboa: Ministério das Obras Públicas, Transportes e Comunicações

Decreto-Lei n. ${ }^{\circ}$ 37/2018 de 4 de Junho. Diário da República n.o 106/2018, Série I. Lisboa: Presidência do Conselho de Ministros

Fabiana, P. (2017). Turismo e mercantilização da cidade. Espaços Vividos e Espaços Construídos, 5(1), 21-28.
Gupta, A., \& Ferguson, J. (1997). Culture, Power, Place: Ethnography at the End of an Era. In A. Gupta \& J. Ferguson (Eds.), Culture, Power, Place. Explorations in Critical Anthropology (pp. 1-29). Durham e Londres: Duke University Press.

Hibou, B. (2011). O ilegal na cidade moderna. In I. Raposo (Ed.), Relatório final do projecto de investigação: PTDC/AUR/71721/2006 - Reconversão e reinserção urbana de bairros de génese ilegal. Avaliação socio-urbanística e soluções integradas de planeamento estratégico (pp. 81-103). Lisboa: Centro de Investigação em Arquitetura, Urbanismo e Design.

Hirsch, E. (1995). Introduction. Landscape: Between Place and Space. In E. Hirsch \& M. O'Hanlon (Eds.), The Anthropology of Landscape. Perspectives on Place and Space (pp. 1-30). Nova Iorque: Claredon Press.

Horta, A. (2000). Constructing Otherness: Nationhood and Immigration Politics in Portuguese Post-colonial Society (tese de doutoramento). Ottawa: Simon Fraser University.

Instituto da Habitação e da Reabilitação Urbana - IHRU (2018). Levantamento Nacional das Necessidades de Realojamento Habitacional. Lisboa: IHRU.

Lages, J. (2017). À Conquista de Justiça Espacial. Intervenções Liminares em Territórios Autoproduzidos na Área Metropolitana de Lisboa (tese de doutoramento). Lisboa: Faculdade de Arquitectura da Universidade de Lisboa.

Lefebvre, H. (1991). The Production of Space. Oxford: Blackwell.

Malheiros, J., \& Esteves, A. (coords.). (2013). Diagnóstico da População Imigrante em Portugal. Desafios e Potencialidades. Lisboa: ACIDI.

Malheiros, J., Vasconcelos, L., \& Alves, F. (2006a), Operação Cova da Moura - Volume I: Diagnóstico. Iniciativa Bairros Críticos.

Malheiros, J., Vasconcelos, L., \& Alves, F. (2006b), Operação Cova da Moura - Volume II: Plano de Ação e Modelo de Gestão. Iniciativa Bairros Críticos.

Massey, D. (2006). For space. Londres: Sage.

Nações Unidas (2017). Report of the Special Rapporteur on adequate housing as a component of the right to an adequate standard of living, and on the right to non-discrimination in this context: Mission to Portugal. Nova Iorque: Nações Unidas.

Raposo, I., \& Carolino, J. (no prelo). Cova da Moura, que Desígnio, que Desenho. Lisboa: Faculdade de Arquitetura da Universidade de Lisboa

Raposo, I., \& Jorge, S. (2017). Qualificação de bairros peri-centrais autoproduzidos em Lisboa e Maputo: virtudes e vicissitudes dos processos. Espaços Vividos e Espaços Construídos, 3(1), 37-50.

Raposo, I. (2009, junho). Intervenção pública num bairro "crítico", o Alto da Cova da Moura. Comunicação apresentada no VI Seminário Internacional Arquitetura e Cosmologia (não publicado).

Raposo, I. (2012). Bairros de génese ilegal: metamorfoses dos modelos de intervenção. In M. Mendes, 
C. Ferreira, T. Sá \& J. Crespo (coords.), A cidade entre bairros (pp. 107-119). Casal de Cambra: Caleidoscópio.

Raposo, I., Carolino, J., Crespo, J., \& Jorge, S. (2012). Os instrumentos urbanísticos como arena social e a perceção do direito à cidade: a regeneração urbana da Vertente Sul de Odivelas. In Atas do VII Congresso Português de Sociologia. Porto: Universidade do Porto.

Salgueiro, T. B. (1985). A habitação na Área Metropolitana de Lisboa. Sociedade e Território, 3, 54-66.

Secretaria de Estado da Habitação - SEH (2017). Para uma Nova Geração de Políticas de Habitação:
Sentido Estratégico, objetivos e instrumentos de atuação. Lisboa: Secretaria de Estado.

Sousa, S. (2012). Registo do Processo - Iniciativa Bairros Críticos. Não publicado.

Souza, M. (2011). A cidade, a palavra e o poder: práticas, imaginários e discursos heterónomos e autónomos na produção do espaço urbano. In A. Carlos, M. Souza \& M. Sposito (Orgs.), A produção do espaço urbano, agentes e processos, escalas e desafios (pp. 149-166). São Paulo: Editora Contexto.

Tuan, Y. (1977). Space and Place. The Perspective of Experience. Londres: University of Minnesota Press.

Sílvia Jorge (aivlisjorge@gmail.com) Faculdade de Arquitetura da Universidade de Lisboa, Grupo de Estudos Sócio-Territoriais, Urbanos e de Ação Local do Centro de Investigação em Arquitetura, Urbanismo e Design GESTUAL-CIAUD, Rua Sá Nogueira, 1349-063 Lisboa

Júlia Carolino (jcarolino@outlook.pt) Faculdade de Arquitetura da Universidade de Lisboa, Grupo de Estudos Sócio-Territoriais, Urbanos e de Ação Local do Centro de Investigação em Arquitetura, Urbanismo e Design GESTUAL-CIAUD, Rua Sá Nogueira, 1349-063 Lisboa 